\title{
Metodoloxías e ferramentas útiles para desenvolver un proxecto de Aprendizaxe-Servizo
}

\author{
Ares-Pernas, Ana; Abad, María José \\ Universidade da Coruña, Departamento de Física e Ciencias da Terra, Campus de Ferrol
}

\section{RESUMO}

Neste traballo recóllese un resumo das metodoloxías empregadas durante os cursos 2015/2016 a 2018/2019 para o deseño e avaliación de varias actividades de Aprendizaxe-Servizo e unha selección de aquelas que resultaron máis útiles, así coma os puntos febles atopados nas mesmas. As actividades realizáronse con distintas entidades e colectivos; persoas en risco de exclusión social, enfermos de Alzheimer ou esquizofrenia e persoas xordas ou con síndrome de Down, o que fixo necesario seleccionar as ferramentas de traballo e avaliación máis axeitadas en cada caso. A clase inversa permitiu aos estudantes acadar de forma máis efectiva aquelas competencias que necesitaban para desenvolver a actividade (adquirir a metodoloxía científica ou manexar material de laboratorio). A rúbrica serviu para avaliar as competencias específicas, xerais e transversais. As citas dos estudantes, participantes, entidades e docentes serviron para a análise cualitativa dos resultados e para detectar outro tipo de competencias, máis persoais, nos estudantes ou para definir os puntos fortes e febles da actividade. As enquisas, diferentes en cada caso e adaptadas para os colectivos que así o precisaban, serviron tamén para analizar cuantitativamente os resultados. Por último, a metodoloxía de Foto-voz serviu para analizar o impacto que tivo nos estudantes o traballo na comunidade.

PALABRAS CHAVE: Rúbrica; citas; foto-voz clase invertida 


\section{CITA RECOMENDADA:}

Ares-Pernas, Ana; Abad, María José (2020): Metodoloxías e ferramentas útiles para desenvolver un proxecto de Aprendizaxe-Servizo. En De la Torre Fernández, E. (ed.) (2020). Contextos universitarios transformadores: Boas prácticas no marco dos GID. IV Xornadas de Innovación Docente. Cufie. Universidade da Coruña. A Coruña (págs. 265-280).

DOI capítulo: https://doi.org/10.17979/spudc. 9788497497756.265

DOl libro: https://doi.org/10.17979/spudc. 9788497497756

\section{ABSTRACT}

In this work a summary of methodologies undertaken during the 2015/2016-2018/2019 courses for the design and evaluation of several Service-Learning projects is presented. In addition, it can be seen a selection of those that were more useful and the weak points observed in them. The activities were performed with different entities and groups: people in risk of social exclusion, people with Alzheimer's disease, schizophrenia or Down syndrome and deaf people; what made it necessary to select the most suitable work and assessment tools in each case. Flipped classroom allowed students to fulfil more effectively those skills they needed to develop the activities (acquire scientific methodology or work with laboratory material). The rubric was useful to evaluate specific, general and transversal competences. The students, users, entities and teacher quotes were useful for the qualitative analysis and to discover other skills, more personal, in the students or to define the strengths and weaknesses of the activity. The surveys, different in each case, and adapted for the groups that needed it, also served to analyze quantitatively the results. Finally, the Photo-voice methodology allowed to analyze the impact that the community work had on students.

KEY WORDS: Rubric; quotes; foto-voice; flipped classroom 


\section{INTRODUCCIÓN}

A aprendizaxe-servizo (ApS) é unha metodoloxía que se ven usando na materia de primeiro curso Fundamentos de Física do Grao en Enxeñaría en Deseño Industrial e Desenvolvemento do Produto durante os últimos catro cursos académicos 2015/2016-2018/2019 e noutras materias que imparten as profesoras membros do GID da UDC RSEn-Fomento da Responsabilidade Social nas enxeñarías. A ApS é unha metodoloxía que nos permite propor situación nas que ten que haber transferencia de coñecementos, resolución de problemas, reflexión crítica, etc... nun contexto real e moitas veces complexo no que os estudantes poderán demostrar as súas competencias resolvendo situación reais. Ao mesmo tempo realizarán un servicio á comunidade o que permite formar aos estudantes non só en contidos senón tamén en valores e desenvolver competencias transversais, profesionais, específicas e competencias de investigación. Ademais, competencias xenéricas como a capacidade de traballo en equipo, habilidades sociais, empatía, creatividade, resolución de problemas, liderazgo e valores cidadás e persoais. Todas estas competencias serían moi difíciles de acadar e avaliar por medio de outras metodoloxías. Debido a isto é moi importante seleccionar as ferramentas máis útiles tanto para deseñar o proxecto, coma para avaliar as competencias nos estudantes implicados nas actividades ApS, sendo esta unha das liñas principais do noso GID. As ferramentas deben proporcionar información suficiente sobre a aprendizaxe e sobre as necesidades ou cambios para a mellora da actividade (Puig 2015 e Puig 2017).

Neste traballo describiranse as actividades ApS realizadas e as metodoloxías de avaliación empregadas durante os cursos académicos 2015/2016 a 2018/2019.

\section{DESCRICIÓN DAS EXPERIENCIAS}

Dende 0 curso 2015/2016 véñense desenvolvendo distintas actividades de ApS na materia Fundamentos de Física no proxecto ApS que leva por título "Aprende Física e Divírtete". Un resumo da evolución das actividades pode verse na Táboa 1. Dende 0 curso 2015/2016 foi aumentando o número de entidades coas que se traballou e, do mesmo xeito, tanto o número de estudantes involucrado coma 0 número de participantes aos que foi dirixido 0 servizo. 
Traballouse con distintas entidades: Cáritas Diocesana de Mondoñedo-Ferrol (CÁRITAS), Saúde Mental Ferrol, Eume e Ortegal (AFAES), Alzheimer Ferrolterra (AFAL), Teima Down Ferrol (TEIMA) e Asociación de Persoas Xordas de Ferrolterra (AXF). Con cada entidade os obxectivos e 0 propio servizo foron diferentes en función das necesidades plantexadas e dos participantes aos que ía dirixido. Na Táboa 2 pódese ver o servizo realizado e os obxectivos en cada caso.

\begin{tabular}{|c|c|c|c|c|}
\hline & $\mathbf{2 0 1 5 / 2 0 1 6}$ & $\mathbf{2 0 1 6 / 2 0 1 7}$ & $\mathbf{2 0 1 7 / 2 0 1 8}$ & $\mathbf{2 0 1 8 / 2 0 1 9}$ \\
\hline Estudantes & 17 & 24 & 51 & 70 \\
\hline & & & CÁRITAS & CÁRITAS \\
& & CÁRITAS & AFAES & AFAES \\
Entidades & CÁRITAS & AFAES & AFAL & TEIMA DOWN \\
& & & TEIMA DOWN & AXF \\
& & 50 & 92 & 176 \\
\hline Usuari@s & 23 & 5 &
\end{tabular}

Táboa 1. Evolución das actividades

\begin{tabular}{|c|c|}
\hline Entidade / Grupo & Descrición e obxectivos do servizo \\
\hline $\begin{array}{l}\text { CÁRITAS } \\
\text { (ADULTOS) }\end{array}$ & $\begin{array}{l}\text { Descrición do servizo: Feira científica sobre a Física para a vida diaria } \\
\text { Obxectivos do servizo: Formación para a vida diaria ou para a procura de emprego sobre temas } \\
\text { como electricidade, óptica, etc... e traballar as habilidades sociais con persoas sen fogar. }\end{array}$ \\
\hline $\begin{array}{c}\text { CÁRITAS } \\
\text { (MENORES) }\end{array}$ & $\begin{array}{l}\text { Descrición do servizo: Taller de Física con experimentos divertidos e Taller de reciclaxe e } \\
\text { reutilización } \\
\text { Obxectivos do servizo: Fomentar o gusto polas ciencias e o pensamento crítico mediante } \\
\text { experiencias de Física divertida en rapaces con alto fracaso escolar. Fomentar o consumo } \\
\text { responsable mediante un taller de separación de residuos, reciclaxe e reutilización }\end{array}$ \\
\hline $\begin{array}{l}\text { AFAES } \\
\text { (ENFERMIDADE } \\
\text { MENTAL) }\end{array}$ & $\begin{array}{l}\text { Descrición do servizo: Feira científica con } 3 \text { stands de Física para a vida diaria e } 3 \text { stands de } \\
\text { reciclaxe e reutilización } \\
\text { Obxectivos do servizo:Formación en temas diferentes aos traballados habitualmente na } \\
\text { entidade (coiro, madeira, xardinería, etc) que poden ser de interese xa que moitos dos } \\
\text { enfermos teñen formación técnica. Fomentar as relación sociais con persoas alleas ao centro }\end{array}$ \\
\hline $\begin{array}{c}\text { AFAL } \\
\text { (ALZHEIMER) }\end{array}$ & $\begin{array}{l}\text { Descrición do servizo: Talleres de reciclaxe e reutilización } \\
\text { Obxectivos do servizo: Fomentar o uso da memoria a través de xogos de separación de } \\
\text { residuos (bingo, adiviñas) que lles permitan comparar os seus recordos coa época actual. } \\
\text { Favorecer a psicomotricidade a través de un taller de reutilización (fabricación de obxectos con } \\
\text { materiais reciclados). Fomentar a relación con persoas alleas ao centro (máis beneficiosa } \\
\text { cando se relacionan con moz@s) }\end{array}$ \\
\hline $\begin{array}{l}\text { TEIMA DOWN } \\
\text { (SÍNDROME } \\
\text { DOWN) }\end{array}$ & $\begin{array}{l}\text { Descrición do servizo: Feira sobre Física e reciclaxe Obxectivos do servizo: Fomentar } 0 \\
\text { consumo responsable dando formación sobre separación de residuos e tipos de plásticos. } \\
\text { Preparación de material adaptado para os usuari@s. }\end{array}$ \\
\hline $\begin{array}{l}\text { AXF } \\
\text { (PERSOAS } \\
\text { XORDAS) }\end{array}$ & $\begin{array}{l}\text { Descrición do servizo: Vídeos educativos adaptados para xordos sobre Física e reciclaxe } \\
\text { Obxectivos do servizo: Deseñar, gravar e editar vídeos adaptados con subtítulos sobre Física e } \\
\text { reciclaxe para que poidan ser usados como formación na propia asociación }\end{array}$ \\
\hline
\end{tabular}

Táboa 2. Resumo do servicio prestado e dos obxectivos do mesmo 
As actividades foron evolucionando e mellorando ao longo dos cursos tendo en conta que hai entidades coas que se leva traballando 4 cursos.

Para que a actividade poida ser ApS é obvio que se necesita definir ben 0 servizo (Táboa 2) pero non menos importante é determinar cales son as aprendizaxes que deben adquirir os estudantes. No caso da materia Fundamentos de Física os estudantes deben ser capaces de por en práctica os contidos da materia ao mesmo tempo que adquiren outras competencias que se poden ver na Táboa 3.

\begin{tabular}{|l|l|}
\hline \multirow{2}{*}{$\begin{array}{l}\text { Competencias } \\
\text { específicas }\end{array}$} & $\begin{array}{l}\text { Traballar de forma efectiva como individuo e como membro de equipos diversos e } \\
\text { multidisciplinares }\end{array}$ \\
\cline { 2 - 2 } & $\begin{array}{l}\text { Capacidade para deseño, redacción e dirección de proxectos en todas as súas } \\
\text { diversidades e fases }\end{array}$ \\
\hline \multirow{2}{*}{ Competencias xerais } & Traballar de forma colaborativa. Coñecer as dinámicas de grupo e o traballo en equipo \\
\cline { 2 - 2 } $\begin{array}{l}\text { Competencias } \\
\text { transversais }\end{array}$ & $\begin{array}{l}\text { Expresarse correctamente, tanto de forma oral coma escrita, nas linguas oficiais da } \\
\text { comunidade autónoma }\end{array}$ \\
\cline { 2 - 2 } & $\begin{array}{l}\text { Desenvolverse para o exercicio dunha cidadanía aberta, culta, crítica, comprometida, } \\
\text { democrática e solidaria, capaz de analizar a realidade, diagnosticar problemas, formular } \\
\text { e implantar solucións baseadas no coñecemento e orientadas ao ben común }\end{array}$ \\
\hline
\end{tabular}

Táboa 3. Competencias que deben acadar os estudantes coa actividade ApS

\section{FERRAMENTAS DE AVALIACIÓN 2015/2016}

Dende o primeiro curso de desenvolvemento da actividade pareceunos moi importante que os estudantes colaborasen no proxecto en todas as súas fases, é dicir, unha vez coñecida a entidade coa que se ía realizar o servicio os estudantes deberían intervir tanto no deseño coma na organización do proxecto aportando ideas de tal forma que considerasen o proxecto coma seu.

Cando aos estudantes se lles plantexa unha nova actividade a primeira dúbida que teñen é para que serve? e como se lles vai cualificar? polo que o proceso de avaliación debe ser 0 máis transparente posible. Para elo construíuse a rúbrica que se pode ver na Figura 1 e que recolle a combinación dos elementos que van ser valorados, é dicir, as competencias (columna da esquerda) cos distintos grados de dominio de dito elemento (fila superior da taboa), que á súa vez recollen e expresan os criterios de avaliación seleccionados (celdas da Táboa). Esta rúbrica púxose a disposición dos estudantes en Moodle e consensuouse na aula 
todos os criterios da mesma. A rúbrica presenta moitas vantaxes para docentes e estudantes: é transparente (con uns obxectivos claros), é un sistema de avaliación homoxéneo, e por tanto moito máis xusto, que permite que varias persoas realicen a avaliación, ou incluso a autoavaliación, mantendo a reproductibilidade. Ademais é a mellor forma de avaliar competencias. Tras avaliar as competencias dos estudantes por medio da rúbrica viuse que a gradación que se tiña asignada non era a axeitada porque non permitía discriminar axeitadamente entre os grupos e decidiuse que debería ser más estrita no seguinte curso.

Como outro método de avaliación deseñáronse enquisas de satisfacción tanto para os estudantes coma para os participantes de Cáritas que, no primeiro ano, eran menores en risco de exclusión social. As enquisas foron diferentes no caso dos estudantes da UDC e no caso dos menores.

\begin{tabular}{|c|c|c|c|c|}
\hline \multicolumn{5}{|c|}{ Actividade Aprendizaxe- Servizo - Avaliación de grupos } \\
\hline $\begin{array}{l}\text { Competencias } \\
\text { avaliadas }\end{array}$ & $\begin{array}{l}\text { Non cumpre (0 } \\
\text { puntos) }\end{array}$ & \begin{tabular}{|l|} 
Cumprimento \\
insuficiente (1 punto)
\end{tabular} & \begin{tabular}{|l} 
Cumprimento \\
suficiente (2 puntos)
\end{tabular} & \begin{tabular}{|l} 
Cumprimento \\
excelente (3 puntos)
\end{tabular} \\
\hline $\begin{array}{l}\text { Traballar de forma } \\
\text { efectiva como } \\
\text { membro equipo } \\
\end{array}$ & $\begin{array}{l}\text { Non se realiza } 0 \\
\text { traballo }\end{array}$ & $\begin{array}{l}\text { Realízase o traballo a } \\
\text { medias }\end{array}$ & $\begin{array}{l}\text { Realízase o traballo pero } \\
\text { non se entrega en prazo }\end{array}$ & $\begin{array}{l}\text { Realízase o traballo e } \\
\text { en prazo }\end{array}$ \\
\hline $\begin{array}{l}\text { Capacidade deseño, } \\
\text { redacción e dirección } \\
\text { de proxectos }\end{array}$ & $\begin{array}{l}\text { Os estudantes non } \\
\text { buscan a información } \\
\text { axeitada e non saben } \\
\text { presentala }\end{array}$ & $\begin{array}{l}\text { Os estudantes buscan } \\
\text { a información axeitada } \\
\text { pero non a sintetizan } \\
\text { axeitadamente }\end{array}$ & $\begin{array}{l}\text { Os estudantes buscan a } \\
\text { información axeitada e } \\
\text { sintetizana de forma } \\
\text { aceptable }\end{array}$ & $\begin{array}{l}\text { Os estudantes buscan } \\
\text { e sintetizan a } \\
\text { información de forma } \\
\text { excelente. }\end{array}$ \\
\hline $\begin{array}{l}\text { Traballar de forma } \\
\text { colaborativa }\end{array}$ & $\begin{array}{l}\text { Os estudantes non se } \\
\text { integran como grupo e } \\
\text { non se adaptan ao } \\
\text { traballo encomendado }\end{array}$ & $\begin{array}{l}\text { Os estudantes non se } \\
\text { integran como grupo } \\
\text { pero sí se adaptan ao } \\
\text { traballo encomendado }\end{array}$ & $\begin{array}{l}\text { Os estudantes intégranse } \\
\text { como grupo pero non se } \\
\text { adaptan ao traballo } \\
\text { encomendado }\end{array}$ & \begin{tabular}{|l|} 
Os estudantes \\
intégranse como \\
grupo e adaptanse ao \\
traballo encomendado \\
\end{tabular} \\
\hline $\begin{array}{l}\text { Comunicarse de } \\
\text { maneira efectiva nun } \\
\text { entorno de traballo }\end{array}$ & $\begin{array}{l}0 \text { grupo non } \\
\text { comunica os } \\
\text { conceptos axeitados e } \\
0 \text { auditorio non os } \\
\text { entende } \\
\end{array}$ & $\begin{array}{l}0 \text { grupo non transmite } \\
\text { os conceptos } \\
\text { axeitados pero o } \\
\text { auditorio enténdeos }\end{array}$ & $\begin{array}{l}0 \text { grupo transmite os } \\
\text { conceptos axeitados pero } \\
0 \text { auditorio non os } \\
\text { entende }\end{array}$ & $\begin{array}{l}0 \text { grupo transmite os } \\
\text { conceptos axeitados e } \\
0 \text { auditorio enténdeos }\end{array}$ \\
\hline $\begin{array}{l}\text { Expresarse } \\
\text { correctamente }\end{array}$ & $\begin{array}{l}0 \text { grupo ten } \\
\text { problemas para falar } \\
\text { en público e adaptarse } \\
\text { ao auditorio } \\
\end{array}$ & $\begin{array}{l}0 \text { grupo non ten } \\
\text { problemas para falar } \\
\text { en público pero non } \\
\text { se adapta ao auditorio }\end{array}$ & $\begin{array}{l}0 \text { grupo ten problemas } \\
\text { para falra en público pero } \\
\text { adáptase ao auditorio }\end{array}$ & $\begin{array}{l}0 \text { grupo fala ben en } \\
\text { público e adáptase } \\
\text { perfectamente ao } \\
\text { auditorio }\end{array}$ \\
\hline Cidadanía & $\begin{array}{l}0 \text { grupo non ten } \\
\text { interese no traballo } \\
\text { coa entidade nin na } \\
\text { repercusión do seu } \\
\text { traballo }\end{array}$ & $\begin{array}{l}0 \text { grupo ten interese } \\
\text { en traballar coa } \\
\text { entidade pero non se } \\
\text { implica o suficiente }\end{array}$ & $\begin{array}{l}0 \text { grupo non ten interese } \\
\text { en traballar coa entidade } \\
\text { pero si se preocupa pola } \\
\text { repercusión do seu } \\
\text { traballo }\end{array}$ & $\begin{array}{l}0 \text { grupo ten interese } \\
\text { en traballar coa } \\
\text { entidade e preocupase } \\
\text { polo resultado do seu } \\
\text { traballo } \\
\end{array}$ \\
\hline
\end{tabular}

Figura 1. Rúbrica de avaliación curso 2015/2016 
No caso dos estudantes, a enquisa constaba de 20 preguntas relacionadas coa convocatoria (tempo, medios e información), os obxectivos (aprendizaxes, transferencia coñecementos), reflexión (problemas comunidade, responsabilidade como cidadán, interese pola entidade, interese polo contacto cos participantes, duración, intensidade e organización (tempo, medios e instalación), coordinación, titoría e avaliación (papel do titor, sistema de avaliación), por último deixábaselles un espazo en branco para os comentarios. No caso dos menores con idades entre os 7 e 16 anos, a enquisa era de 10 preguntas nunha linguaxe máis sinxela, para que puidera ser contestada por todos, acerca de se lles gustara visitar a universidade, coñecer aos estudantes, facer os experimentos e as experiencias de reciclaxe e o máis importante se lles axudara a comprender mellor cousas que tiñan estudado na aula.

Ademais, tamén se realizou unha reunión coa entidade para analizar os puntos fortes e febles da actividade, recollendo todos os datos no diario de campo do profesor.

\section{FERRAMENTAS DE AVALIACIÓN 2016/2017}

Tras a experiencia do curso 2015/2016 viuse que non era suficiente 0 análise ao final da experiencia senón que debería estar presente noutros momentos da actividade, polo que se fixo unha enquisa inicial ao alumnado, que se pode ver na Táboa 4.

\begin{tabular}{|l|}
\hline Que foi o que te motivou a participar na actividade ApS \\
\hline Pensas que o servizo que vas realizar á comunidade vai resultar útil á mesma? \\
\hline Cres que vai ser sinxelo para tí obter as competencias da materia? \\
\hline Coñecías a entidade coa que vas traballar? \\
\hline Resúltache interesante o traballo en grupo cos teus compañeiros? \\
\hline Participaras antes nalgunha acción de voluntariado ou servicio á comunidade? \\
\hline $\begin{array}{l}\text { Coméntanos calquera cousa que che pareza interesante acerca das túas expectativas sobre a } \\
\text { actividade }\end{array}$
\end{tabular}

Táboa 4. Preguntas de avaliación inicial da actividade 
A avaliación das competencias seguiuse a realizar coa mesma rúbrica (Figura 1) pero variando a escala de cualificación para que fose máis estrita e permitise discriminar entre grupos, tal e como se pode ver na Táboa 5 .

Escala de cualificación: Nota máxima 2

Non participou: 0; Ata 4 puntos:0,25; Ata 6 puntos: 0,5; Ata 8 puntos: 0,75; Ata 10 puntos:1; Ata 12 puntos: 1,25; Ata 14 puntos: 1,5; Ata 16 puntos: 1,75; Ata 18 puntos: 2

Táboa 5. Nova escala de gradación para a rúbrica

Comezouse a traballar cunha nova entidade, AFAES, e foi necesario deseñar unha nova enquisa, adaptada neste caso a persoas adultas con dificultades nalgún caso para a lectura fluída. Na enquisa fixéronselles 10 preguntas relacionadas cos contidos do curso (Física e reciclaxe), a metodoloxía (explicacións e exemplos), organización (duración, materiais empregados, aula) e deixóuselles un espazo para as súas opinións persoais.

0 feito de incorporar as cuestións ao principio da actividade, permitiunos comparar as expectativas e preocupacións que os estudantes tiñan ao inicio co que reflectía na enquisa final, pero aínda así, non resultou suficiente. Interesábanos comprender as vivencias dos estudantes respecto ao seu propio aprendizaxe académico e desenvolvemento persoal e era necesario sistematizar un método que nos permitise recoller as súas vivencias para poder facer un análise cualitativo.

Según Yorio y Ye (2012), os datos obtidos da análise cualitativa proporcionan información sobre a relación entre a aplicación da ApS e os resultados académicos. Os estudantes serán os protagonistas en primeira persoa, e quen describan a súa experiencia. Tratase de analizar a dimensión persoal (inseguridade, vivencias positivas, satisfacción) e as aprendizaxes académicas (imprevistos, aprender para ensinar, coñecemento, realidade social) (Chiva-Bartoll 2015) 


\section{FERRAMENTAS DE AVALIACIÓN 2017/2018}

Nese curso recolléronse as reflexións dos estudantes en distintos puntos da actividade a través da plataforma Moodle mediante a ferramenta "Tarefa". Para evitar dúbidas acerca do que debían poñer, en cada entrada dábaselles unha pequena pista que lles servira de guía sen condicionalos. Na Táboa 6 poden verse as indicacións de cada entrada.

\begin{tabular}{|l|l|l|}
\hline Tarefa 1 & $\begin{array}{l}\text { Reunión } \\
\text { inicial }\end{array}$ & $\begin{array}{l}\text { Comenta as motivacións, dúbidas ou expectativas que tes acerca da } \\
\text { actividade e do grupo de participantes cos que che tocou traballar }\end{array}$ \\
\hline Tarefa 2 & $\begin{array}{l}\text { Visita aos } \\
\text { centros }\end{array}$ & $\begin{array}{l}\text { iCómo te sentiches ao entrar en contacto co grupo de participantes? iEn } \\
\text { qué aspectos a túa impresión coincide co que tiñas imaxinado e que } \\
\text { aspectos non coinciden?. Reflexiona sobre si tiñas estereotipos ou } \\
\text { prexuízos. Coñecidos os participantes: cidentificas algunha preocupación } \\
\text { ou dúbida ante o desenvolvemento da actividade? }\end{array}$ \\
\hline Tarefa 3 & $\begin{array}{l}\text { Primeira } \\
\text { titoría grupo }\end{array}$ & $\begin{array}{l}\text { Dende a túa experiencia con esta actividade e hasta este momento } \\
\text { identifica, describe e avalía as vantaxes e desvantaxes do traballo en } \\
\text { grupo e da titoría coa profesora no proceso de selección de propostas } \\
\text { para a realización do taller }\end{array}$ \\
\hline Tarefa 4 & $\begin{array}{l}\text { Terceira } \\
\text { titoría }\end{array}$ & $\begin{array}{l}\text { Avalía todo o procedemento de preparación do taller, os puntos fortes e } \\
\text { febles e cales son as túas expectativas de cara á xornada final }\end{array}$ \\
\hline Tarefa 5 & $\begin{array}{l}\text { Análise } \\
\text { final }\end{array}$ & $\begin{array}{l}\text { Tralo desenvolvemento da actividade icómo foi a experiencia nos centros } \\
\text { tanto a nivel persoal coma académico?. Analiza se se cumpriron as túas } \\
\text { expectativas }\end{array}$ \\
\hline
\end{tabular}

Táboa 6. Tarefas Moodle

Coa axuda do software de análise cuantitativo WebQDA analizáronse as distintas citas recollidas o que nos permitiu non só avaliar a evolución dos estudantes ao longo da actividade senón tamén identificar unha serie de competencias a nivel persoal que non eramos quen de ver co análise cuantitativo. Na Figura 2 pode verse unha gráfica comparativa das preocupacións iniciais dos estudantes coas competencias observadas ao final da actividade para 0 grupo que traballou con Cáritas e na Figura 3 os puntos positivos extraídos da análise das citas en Moodle para todos os grupos.

Algúns exemplos das citas recollidas en Moodle e que serviron para realizar o análise: 
"Pareceume unha actividade moi interesante e importante para a nosa profesión pois debemos ser capaces de explicar ante un público o noso produto" (Cita Moodle, 13 de Maio 2018, estudante grupo AFAES)

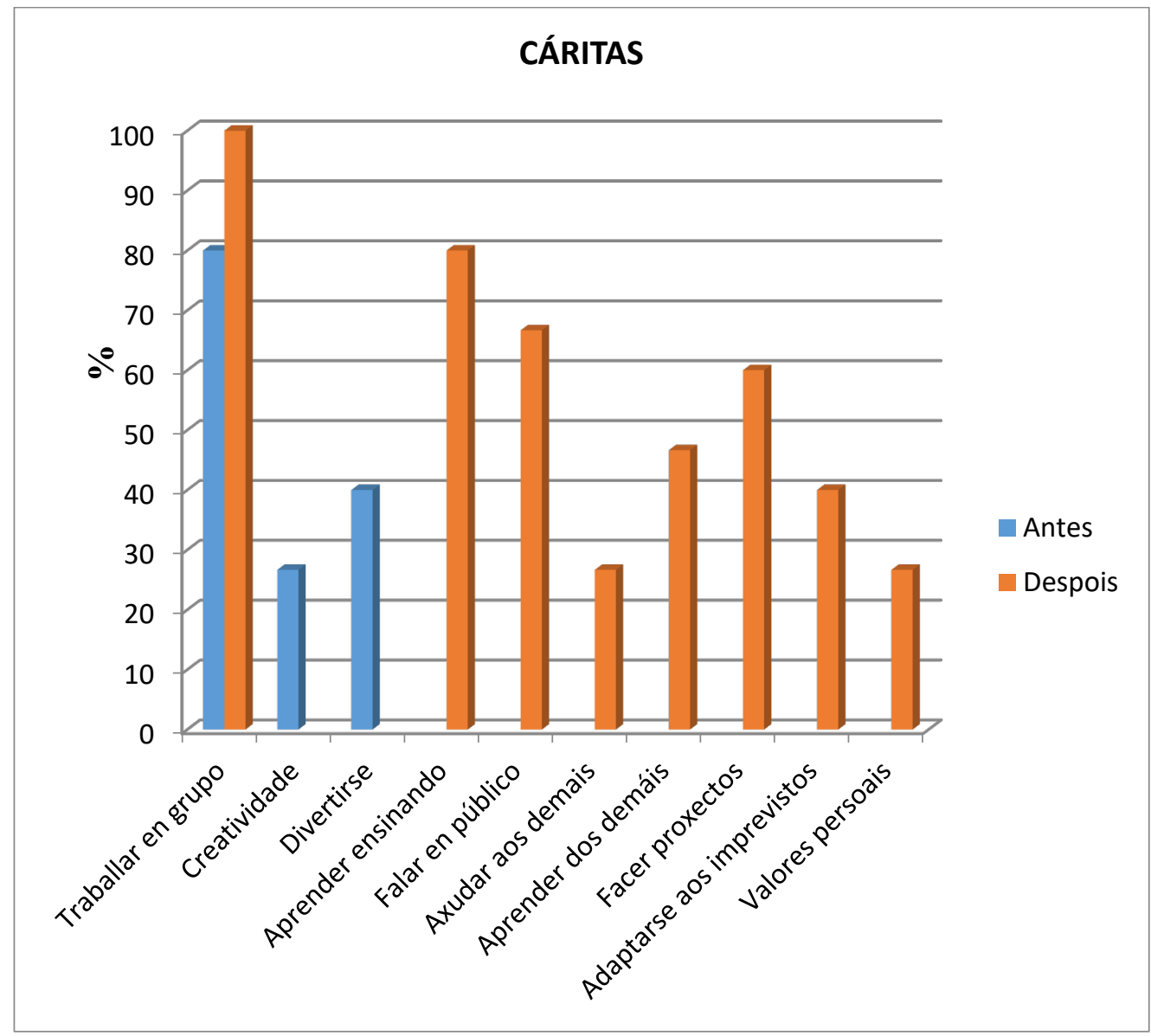

Figura 2. Análise cualitativo das citas antes e despois actividade Cáritas 


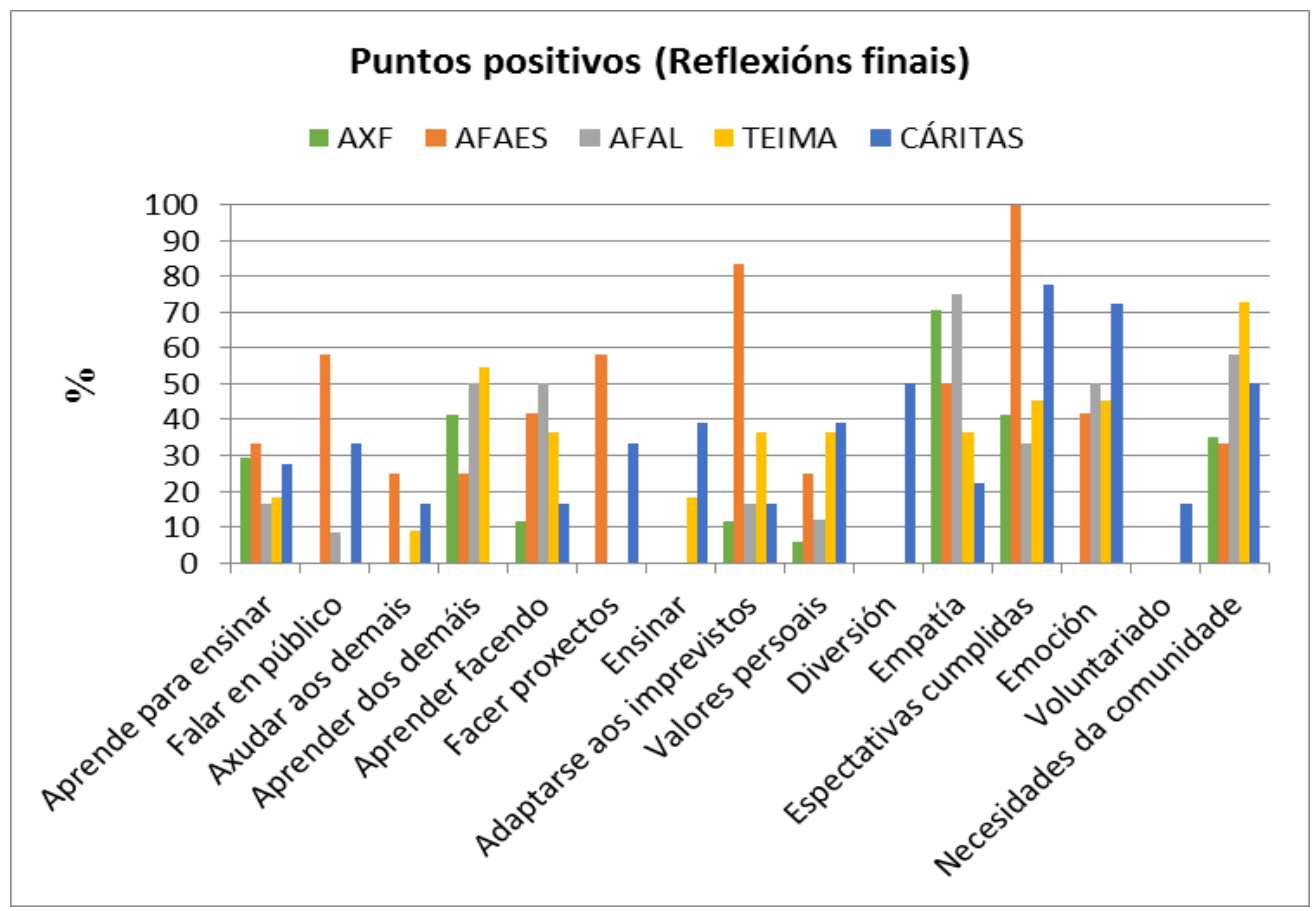

Figura 3. Reflexións finais extraídas da análise cualitativa

"Había persoas con formación técnica entre os participantes, nunca pensei que algún de nós podería verse nunha situación coma esta" (Cita Moodle, 11 Maio 2018, estudante grupo AFAES)

"Valoro ter que aprender para ensinar, non é tan fácil dar clase, tes que aprender moi ben todo o que vas explicar" (Cita Moodle, 30 Abril 2018, estudante grupo AFAL)

Tamén foi necesario deseñar novas enquisas con pictogramas para o novo grupo con Síndrome de Down.

\section{FERRAMENTAS DE AVALIACIÓN 2018/2019}

Neste curso incorporáronse dúas novas ferramentas, a primeira foi a clase inversa ou invertida. A clase invertida é unha metodoloxía pedagóxica na que 0 ensino cambia o espazo de aprendizaxe en grupo ao espazo de aprendizaxe individual. 0 espazo grupo transfórmase 
nun ambiente dinámico, interactivo onde 0 ensinante guía aos estudantes para aplicar os conceptos. A adquisición dos coñecementos móvese cara afora da aula e foméntanse as actividades interactivas entre estudantes e profesor na aula, o que ten impacto positivo nos estudantes de cara á materia (Pulcini 2018). Na aula de Fundamentos de Física, a metodoloxía empregouse para ensinar aos estudantes como desenvolver os experimentos empregando 0 método científico. A profesora gravou un vídeo realizando un experimento, para que visen os pasos a seguir. Os estudantes debían ver o vídeo antes da titoría, para poder discutir nela as dúbidas que lles xurdisen

A segunda das ferramentas empregadas foi Fotovoz, que é unha técnica de fotografía participativa que busca dar voz a través da imaxe (Leung 2017). Coa fotografía preténdese representar vivencias e percepcións das persoas que realizan a foto. As cámaras colocáronse nas mans de 6 estudantes, que reflexaron as preocupacións dentro da súa comunidade usando as imaxes. Os estudantes debían describir a foto e 0 que nela acontece, dando as razóns polas que se tomou esa e non outra e o significado que ten para eles. Pode suceder que cousas que non se tiñan reflexadas nas citas aparezan con esta técnica. Pode ser unha boa ferramenta para reflectir os problemas na comunidade e motivar cambios positivos na mesma, a idea é compartir estas fotos con todo o mundo para visibilizar unha situación ou necesidade. Unha das fotos elixidas ten por título "Educando para a solidaridade" e pode verse na Figura 4.

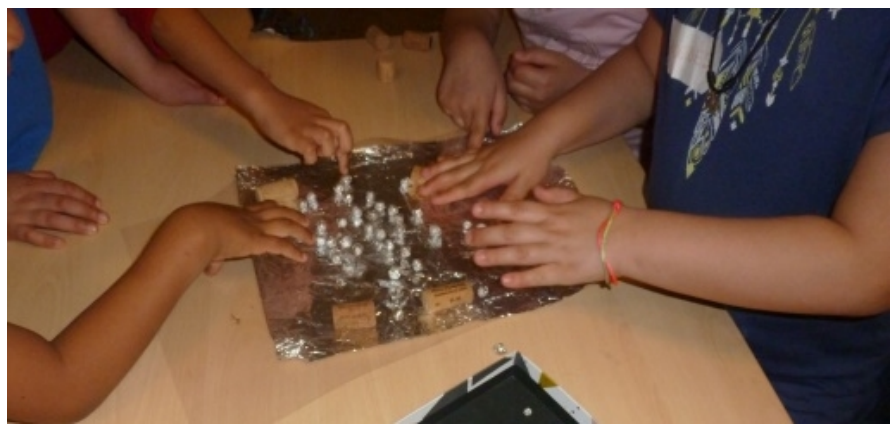

Figura 4. Unha das fotografías elixidas na técnica Fotovoz 
Tamén se levou a cabo difusión nos medios (Moodle, prensa), algo moi importante para estender os resultados ao resto da comunidade e visibilizar as necesidades da mesma.

Para rematar un resumo das ferramentas empregadas ao longo dos cursos pode verse na Táboa 7.

\begin{tabular}{|c|c|c|c|c|}
\hline & $2015 / 2016$ & $2016 / 2017$ & $2017 / 2018$ & $2018 / 2019$ \\
\hline & & & & Rúbrica \\
& & & Rúbrica & Enquisas \\
Sistemas de & Rúbrica & Rúbrica & Fotos \\
avaliación / & Enquisas & Enquisas & Fouisas & Diarios de campo \\
Evidencias & Fotos & Fotos & Tares & Tarefas Moodle \\
& & Diarios de campo de campo & Flipped classroom \\
& & & Tarefas Moodle & Foto voz \\
& & & Difusión \\
\hline
\end{tabular}

Táboa 7. Resumo das ferramentas empregadas ao longo dos cursos da actividade

\section{PUNTOS DE MELLORA 2019/2020}

Ademais das suxestións recollidas de todos os participantes hai certas melloras que nos gustaría incorporar nos seguintes cursos. Por unha parte, gustaríanos estender a ferramenta Fotovoz a todos os participantes, utilizar a Clase invertida noutros puntos da actividade e crear algunha actividade en colaboración con outras materias do centro ou doutros centros. Ademais, gustaríannos deseñar unha rúbrica para avaliar o proxecto e así intentar mellorar 0 proceso de detección de puntos febles, e que esta facilite 0 traballo de profesores e entidades (Campo 2015, Puig 2015, Puig 2017).

Gustaríanos fomentar máis a autoavaliación e/ou a coavaliación na aula fronte á heteroavaliación, para o que se deseñarán novas rúbricas ao respecto.

Tamén sería interesante fomentar máis a celebración e medir o impacto social analizando máis en profundidade puntos como se se cubriron as necesidades e os cambios poden ser sostibles, se se crearon espazos de participación e reflexión, se se desenvolveron nos casos que aplique competencias para á inserción no mundo laboral (brecha teoría-práctica, traballo 
en equipo, habilidades comunicativas, iniciativa, liderazgo, autocoñecemento das destrezas, posibilidades de traballar con outros profesionais para comprender a complexidade do campo profesional), en xeral, se os saberes transmitidos á comunidade va ser útiles a longo prazo (Campo, 2015)

\section{CONCLUSIÓNS}

Durante os cursos que se leva desenvolvido a actividade utilizáronse distintas ferramentas coa intención de extraer toda a información necesaria da experiencia e avaliar axeitadamente as competencias adquiridas polos estudantes. A principal conclusión é que non existen bos nin malos instrumentos de avaliación, senón instrumentos axeitados ou non aos obxectivos e características da avaliación exposta. É necesario seguir mellorándoos, sempre e cando estes aporten datos para favorecer 0 impacto na comunidade e nos nosos estudantes.

\section{REFERENCIAS}

Campo, L. (2015) Una rúbrica para evaluar y mejorar los proyectos de aprendizaje servicio en la universidad. RIDAS, Revista Iberoamericana de Aprendizaje-Servicio, 1, 91-111 Chiva-Bartoll 0., Corbatón-Martínez, R.\& Capella-Peris, C. (2015) Efectos académicos y personales del aprendizaje-servicio en alumnado de didáctica de la expresión corporal y juegos motores: Estudio cualitativo. Revista Digital de Educación Física, 36

Leung, M.M., Al. Agaronov, T., Entwistle, L, Harry, J., Sharkey-Buckley, N. Freudenberg (2017) Voices through cameras: using photovoice to explore food justice issues with minority youth in East Harlem, New York, Health Promotion Practice, 18 (2), 211-270

Puig, J.M., Battle R.., Breu R., Campo L., de la CerdaM., Gijón M., Graell, M, Martín X., Palos J., Ramoneda A \& Rubio L., (2015) ¿Cómo realizar un proyecto de aprendizajeservicio. 11 ideas clave. Barcelona, Editorial Graó

Puig J., Xus M., Rubio L. (2017) ¿Cómo evaluar los proyectos de aprendizaje-servicio?. Voces de la Educación, 2 (2), 122-132 
Pulcini,B. \& Dennett, E. (2018) Increasing completion and cutting costs: an examination of how the flipped classroom and one-room schoolhouse models benefit community colleges, Community College Journal of Research and Practice, 42 (10), 708-711

Yorio, P.L.\& Ye, F. (2012) A Meta-analysis on the effects of service-learning on the social, personal and cognitive outcomes of learning. Academy of Management Learning and Education, 11 (1), 9-27 
